\title{
Portugal 1300: Poder e Escassez no final da Idade Média
}

\section{Rudyard Rezende Vera *}

DOI: 10.11606/issn.2318-8855.v10i2p751-776

Resumo: O presente artigo tem como objetivo analisar as relaçóes de poder e a agência real em momentos de escassez e carestia em Portugal na Baixa Idade Média. Para isso, utilizaremos algumas crônicas analisadas no projeto "Fome, clima e abastecimento em Portugal no Final da Idade Média" (Portugal 1300), um grupo de pesquisa CNPq criado em julho de 2019 em parceria com a Université Libre de Bruxelles, e cuja função é abastecer uma plataforma virtual denominada QFAME, um repertório de menções à fome nas fontes escritas do Ocidente, do século VIII ao século XV. Através da investigação desses documentos, buscaremos evidenciar também como é possível visualizar o processo de centralização política em Portugal na Baixa Idade Média, a partir da agência real retratada pelos cronistas portugueses Fernão Lopes e Rui de Pina em face da fome e da escassez nas fontes analisadas pelo Portugal 1300.

Palavras-chave: Baixa Idade Média, Fome, Portugal, QFame.

\footnotetext{
* Graduando em História na Universidade de São Paulo (USP) e membro do Laboratório de Estudo Medievais (LEME-USP). Atualmente, desenvolve uma pesquisa de Iniciação Científica, sob orientação do Prof. Marcelo Cândido da Silva (DH-FFLCH/USP), e com financiamento da Fundação de Amparo à Pesquisa do Estado de São Paulo (FAPESP). E-mail para contato: rudyardvera@usp.br
} 


\section{O poder na Idade Média}

Portugal 1300: Poder e Escassez no final da Idade Média

Introdução

Fome, clima e abastecimento em Portugal no Final da Idade Média

O presente artigo foi desenvolvido a partir das reflexões preliminares do projeto "Fome, clima e abastecimento em Portugal no Final da Idade Média" (Portugal 1300), um grupo de pesquisa CNPq criado em julho de 2019, vinculado ao Laboratório de Estudos Medievais da Universidade de São Paulo (LEME-USP) e à cátedra Jaime Cortesão. Tal projeto é fruto de uma parceria com a Université Libre de Bruxelles e busca, através da leitura das fontes portuguesas da Baixa Idade Média, alimentar uma plataforma virtual denominada QFame. Partindo do recenseamento de todas as menções à fome nas fontes escritas da cristandade medieval, a plataforma tem como objetivo disponibilizar fichas digitais que servirão como ferramentas de pesquisa. Através dessas fichas e utilizando palavras-chave relacionadas às suas pesquisas, os historiadores poderão usar a plataforma como uma ferramenta de acesso às fontes medievais. Dessa forma, nosso projeto busca utilizar a tecnologia como forma de inovar e aperfeiçoar a pesquisa histórica.

A partir da leitura dos documentos portugueses da Baixa Idade Média, o projeto "Portugal 1300" busca alimentar essa plataforma e produzir mapas interativos que possibilitem a visualização espacial das menções às guerras e aos fenômenos climáticos e de abastecimento em Portugal nesse período. Em outras palavras, buscamos realizar um estudo da conjuntura sócio-econômica portuguesa entre os séculos XIII e XV através de um recenseamento dos casos de fome nas fontes lusitanas. De maneira geral, o projeto tem como objetivo estudar a "conjuntura de 1300" em Portugal à luz dos estudos mais recentes sobre a bacia do Mediterrâneo no 


\section{O poder na Idade Média}

Rudyard Rezende Vera

final da Idade Média. ${ }^{1}$ Após a confecção dessas fichas, tais dados serão introduzidos no QGIS por outros membros do projeto "Portugal 1300". O QGIS é um programa que permite a confecção de mapas virtuais e, através dele, produziremos uma cartografia digital da fome em Portugal no final da Idade Média que será disponibilizada on-line de maneira acessível aos pesquisadores.

Além disso, o projeto também tem papel importante na formação de jovens pesquisadores, pois possibilita o contato direto com fontes primárias no decorrer da confecção das fichas, ao mesmo tempo em que os insere em debates historiográficos sobre a natureza e amplitude da crise no final da Idade Média, tema amplamente discutido desde a metade do século XX. ${ }^{2}$

Antes de passar para os objetos produzidos pelo grupo "Portugal 1300", faz-se necessário desenvolver brevemente o conceito "conjuntura de 1300", utilizado algumas linhas acima. A historiografia produzida a partir da década de 1950 marcada por autores como Michael Postan, Georges Duby e Guy Bois - começou a definir o período pós crescimento dos séculos XI a XIII como um contexto de crise,

\footnotetext{
${ }^{1}$ Como, por exemplo, as obras: BOURIN, Monique, DRENDEL, John et MENANT, François (org.) Les Disettes dans la conjuncture de 1300 en Méditerranée Occidentale. Collection de L'École Française de Rome, 450, Roma: École française de Rome, 2011; BOURIN, Monique, MENANT, François et FIGUEIRAS, Lluís To (org). Dynamiques du Monde Rural dans la Conjoncture de 1300. Échanges, Prélêvements et Consommation en Méditerranée Occidentale. Collection de L'École Française de Rome, 490, Roma: École française de Rome, 2014

${ }^{2}$ Uma enorme quantidade de obras já foi produzida por esse debate, todas contribuindo para o melhor desenvolvimento da questão. Cito aqui algumas mais recentes e com as quais este artigo dialogará ao longo das próximas páginas: BOURIN, Monique, DRENDEL, John et MENANT, François (org.) Les Disettes dans la conjuncture de 1300 en Méditerranée Occidentale. Collection de L'École Française de Rome, 450, Roma: École française de Rome, 2011; BOURIN, Monique, MENANT, François et FIGUEIRAS, Lluís To (org). Dynamiques du Monde Rural dans la Conjoncture de 1300. Échanges, Prélêvements et Consommation en Méditerranée Occidentale. Collection de L'École Française de Rome, 490, Roma: École française de Rome, 2014; MONCLÚS, Pere i Benito. El Rey frente à la Carestía. Polítiacas Frumentarias de Estado en la Europa medieval. Lleida: Milenio, 2018 e MONCLÚS, Pere Benito Y e OLIVA HERRER, H. R., ed.: Crisis de subsistencia y crisis agrarias em la Edad Media, Sevilla, 2007.
} 


\section{O poder na Idade Média}

\section{Portugal 1300: Poder e Escassez no final da Idade Média}

marcado não só pelo fim da conjuntura de expansão populacional dos séculos anteriores, mas pela inversão desse contexto de crescimento (POSTAN, 1973, p. 213) ou seja, por uma regressão causada pela fome, pela peste e pela guerra. Para Michael Postan e Georges Duby, essa seria a justificativa para os efeitos devastadores da peste de 1347 no Ocidente medieval, já que teria atingido uma população generalizadamente enfraquecida por crises alimentares decorrentes de uma estagnação tecnológica (DUBY, 1995, p. 24-45).

A partir da década de 1990, contudo, novas abordagens começaram a surgir e confrontar essa visão de uma depressão sistêmica e global no século XIV. Em primeiro lugar, graças aos historiadores como David Stone, passou-se a encarar a "conjuntura de 1300" como uma crise que não atingiu toda a Europa da mesma maneira e ao mesmo tempo. Além disso, também começou a se desenvolver a noção de resiliência ${ }^{3}$, evidenciando o papel dos camponeses como personagens ativos de seu tempo e não meros espectadores das dificuldades apresentadas. Em outras palavras, passou-se a considerar a ação da população durante os fenômenos de escassez e carestia, não mais encarando-a como grupo passivo e à mercê da natureza. Assim, os historiadores dessa vertente - como David Stone, François Menant e Monique Bourin - pararam de negligenciar a ação dos indivíduos no aumento da produção agrícola e se posicionaram contra a corrente que analisava tais crises como acontecimentos determinados por fatores totalmente fora do controle desses indivíduos (STONE, 2005, p.15-18).

Essas novas interpretações, nas quais se insere este artigo, baseiam-se na

\footnotetext{
${ }^{3} \mathrm{O}$ conceito de resiliência vem da termodinâmica e diz respeito à capacidade que determinado material tem de se modificar quando confrontado com determinadas pressões e temperaturas. Transferindo o conceito para a história, podemos entender resiliência como a adaptabilidade dos indivíduos frente situações de dificuldades.
} 


\section{O poder na Idade Média}

Rudyard Rezende Vera

análise minuciosa das discrepâncias regionais da cristandade medieval e buscam, assim, revisitar a historiografia da crise do século XIV, mostrando como cada região agia frentes a situações de carestia e como a atribuição genérica de uma "crise sistêmica" a toda a Europa é inviável. Assim, os novos estudos expõem a capacidade de ação autônoma do camponês, e a importância da conjuntura geográfica e temporal de cada ocasião de carestia (BOURIN, MENANT E FIGUEIRAS, 2014, p. 10-14). Como exemplo referencial, temos François Menant, que argumenta que, como o clima ibérico não é tão extremo, as ocasiões de carestia teriam base em situações bélicas e de fiscalidade - diferentemente daquelas ocasionadas em regiões como as atuais Bélgica e Holanda (MENANT, 2007, P. 47). Tais afirmações têm grande impacto em nossa análise, pois justificam o fichamento não somente das menções à "fome", mas nos faz atentar, também, para os demais fenômenos de abastecimento - que se originam nesses contextos expostos. É importante ressaltar, porém, que tal análise regional ainda não foi feita para o caso específico de Portugal e é este o objetivo do grupo "Portugal 1300". Além disso, é justamente essa tendência ao estudo das diferenças regionais que nos inspirou a confeccionar mapas digitais, ferramentas essenciais aos novos estudos e idealizadas a partir do conceito de Humanidades Digitais. $^{4}$

É partindo dessa nova historiografia que o projeto "Portugal 1300" iniciou suas atividades. De julho de 2019 até a produção deste artigo, as seguintes fontes já foram lidas e analisadas: Crônica de D. Pedro (volume único), Crônicas de D. Fernando (3 volumes), Crônicas de D. João (2 volumes), Crônicas dos Carmelitas (2 volumes) e as Crônicas de Ruy de Pina (que contém as histórias dos reis portugueses de D. Sancho I

\footnotetext{
${ }^{4}$ Sobre o conceito de Humanidades Digitais: GUERREIRO, Dália e BORBINHA, José Luís. Humanidades Digitais: novos desafios e oportunidades. Revista Internacional del Libro, Digitalización e Bibliotecas, vol. 2, n. 2, 2014 e ALVES, Daniel. Humanidades Digitais e Investigação Histórica em Portugal: perspectiva e discurso (1979-2015). Práticas da História, vol. 1, n. 2, 2016, p. 89-116.
} 


\section{O poder na Idade Média}

\section{Portugal 1300: Poder e Escassez no final da Idade Média}

até D. João II). Tal processo resultou na produção de aproximadamente 650 fichas, que foram expostas na Jornada Portugal 1300, em novembro de 2019, na cátedra Jaime Cortesão. Nesse evento, foi explorada a evidente conexão entre os conflitos e as ocasiões de carestia nas fontes analisadas até o momento, aspecto exposto visualmente por um atlas digital realizado através do QGIS. Nesse mapa, pudemos ver como as menções à fome e aos conflitos (guerras e cercos) se sobrepunham, indicando a característica antrópica dessas ocasiões de carestia, algo percebido também em outras regiões da cristandade medieval (MENANT, 2007, p. 47).

Dos documentos analisados até o momento, foram discutidos neste trabalho: as Crônicas de D. Pedro I, as Crônicas de D. Fernando, as Crônicas de D. João e as Crônicas de D. Afonso V. Os três primeiros títulos foram produzidos por Fernão Lopes, cronista português nascido em torno de 1380 e falecido por volta de 1460 e que produziu entre 1418 e 1459 uma considerável quantidade de textos sobre a vida dos monarcas lusitanos. Tais documentos foram escritos a partir do pedido de D. Duarte para que se produzisse "a crônica de todos os reis de Portugal, incluindo seu pai, D. João I." (MALEVAL, 2010, p. 20-22). A solicitação é datada de 1419 e foi oficializada em 1434 através de uma carta régia. Nas palavras do rei, "poer em caronyca a estória dos Reys que antygamente em Portugal foram Esso mesmo os grandes feytos e altos do muy virtuoso E de grãdes virtudes ElRey meu Senhor e padre cuja alma deus aja" (MALEVAL, 2010, p. 20-22).

A autoria das Crônicas de D. Afonso V, por sua vez, é assunto de debate. Acredita-se que o primeiro autor desse documento foi Gomes Eannes de Azurara e que este cronista teria escrito a primeira parte da crônica, até a morte do infante D. Pedro. Tendo esse autor falecido em torno de 1472, durante a elaboração do documento, Ruy de Pina continuou o trabalho inacabado em seu próprio nome e, 


\section{O poder na Idade Média}

Rudyard Rezende Vera

quando finalizado, entregou o livro ao rei D. Manuel. Contudo, apesar dessa dupla autoria, os especialistas defendem que isso não prejudica o entendimento da crônica (ALMEIDA, 1977, p. 581).

A escolha de tratar neste artigo esses documentos dentre todos os analisados pelo projeto "Portugal 1300" até o momento se justifica, pois, as quatro produções se iniciaram a partir de pedidos da monarquia portuguesa e consagraram seus autores como cronistas oficiais de Portugal, Fernão Lopes em 1434 e Rui de Pina em 1497. Desta forma, o discurso existente nesses textos exibe uma narrativa sobre a monarquia portuguesa solicitada por ela mesma. Além disso, é possível também analisar nessas quatro crônicas as reações dos reis portugueses frente aos momentos de dificuldade, sejam ocasiões de fome, de doenças ou de guerra - e, com isso, abordar as relações de poder em Portugal na Baixa Idade Média. Dessa forma, o objetivo deste artigo é mostrar a ação real e dos poderes locais nos períodos de carestia e fome, buscando também abordar o fortalecimento do poder real português, principalmente sob a dinastia de avis, a partir das ações reais em momentos de carestia.

Por fim, é importante ressaltar o impacto do projeto "Portugal 1300" no contexto em que estamos vivendo neste ano de 2020. Problemas atuais envolvendo a epidemia da COVID 19 aumentaram o interesse de pesquisadores e do público nas epidemias do passado. Jacques Le Goff, na apresentação do volume "As doenças têm história", escreveu que "a doença pertence à história, em primeiro lugar, porque não é mais que uma ideia, um certo abstrato numa complexa realidade empírica" e que o "corpo sofredor" viria a se transformar em um objeto privilegiado de estudo dos historiadores ao passo que o poder real se tornava um gestor progressivamente mais poderoso da saúde (LE GOFF, 1985, p. 7-8). 


\section{O poder na Idade Média |}

Portugal 1300: Poder e Escassez no final da Idade Média

\section{As fontes portuguesas da Baixa Idade Média}

As fontes analisadas ao longo desses primeiros meses de pesquisa e que foram abordadas neste artigo constituem crônicas régias, ou seja, escritos que discorrem sobre os acontecimentos dos reinados de D. Pedro I, D. Fernando, D. João I e, por fim, D. Afonso V. Como mencionado acima, os três primeiros documentos foram produzidos por Fernão Lopes, cujo trabalho era produzir uma narrativa sobre a chegada de D. João I no poder, e que teve como resultado essa trilogia protagonizada por D. Pedro (1357-1367), D. Fernando (1367-1383) e D. João (1385-1433). Iniciada em 1434, essa tarefa, solicitada pelo rei D. Duarte a Fernão Lopes, que já era Guarda-Mor da Torre do Tombo desde 1418, significava a realização de um trabalho para historiar as monarquias portuguesas (GUIMARÃES, 2004, p. 31).

Sendo Guarda-Mor da Torre do Tombo, Fernão Lopes teve acesso amplo à documentação lá presente, como a Chancelaria de D. Pedro I, as atas das Cortes de 1361 e o testamento deste mesmo rei. Partindo dessa documentação o cronista descreve com riqueza de detalhes cenas como a morte dos assassinos de Inês de Castro, no capítulo 31 da Crônica de D. Pedro I. Além disso, também foi discutida a influência narrativa dos textos de Pero Lopez de Ayala, cronista de Castela, nos trabalhos de Fernão Lopes, tendo em vista que o segundo teve grande contato com as obras do primeiro ao longo da produção de sua trilogia (GUIMARÃES, 2004, p. 44)

Esse acesso aos documentos disponíveis e a construção da representação da própria monarquia portuguesa permitem atribuir a Fernão Lopes o título de "homem de saber", conceito elaborado por Jacques Verger em sua obra "Homens e Saber na Idade Média". Para Verger, nos séculos XIV e XV o poder constituía uma relação que 


\section{O poder na Idade Média}

Rudyard Rezende Vera

envolvia o livro, pois era pela leitura que os homens cultos "obtinham seu saber e, portanto, a própria justificação de seu papel social. Era nos livros e nos arquivos que eles tinham, que eles consignavam e conservavam suas decisões e suas opiniões" (VERGER, 1999, p. 112). Desta forma, designar a Fernão Lopes essa classificação de "homem de saber" não seria falsear a realidade, já que essa terminologia compreende “o domínio de um certo tipo e de um certo nível de conhecimento [e a] reivindicação, (...), de certas competências praticas fundadas precisamente sobre os saberes previamente adquiridos" (VERGER, 1999, p. 16 e GUIMARÃES, 2004, p. 45).

Nas palavras de Marcella Lopes Guimarães, "toda a atividade profissional do homem de saber se fundava na convicção de uma utilidade social bastante prática". Sendo Guarda-Mor da Torre do Tombo e cronista oficial de Portugal a partir de 1434, tal utilidade social de Fernão Lopes pode ser entendida como seu papel de cronista régio, cuja função mais imediata foi narrar a história dinástica portuguesa. É importante ressaltar também que, tendo vivido de $1382^{5}$ a 1460 , o cronista vivenciou diferentes ações reais e formas de reinar, para as quais ele certamente tinha opiniões próprias. Dentre esses episódios, pode-se destacar o período conturbado que foi a regência do infante $D$. Pedro durante a menoridade de $D$. Afonso $V$ e que resultou na batalha de Alfarrobeira. Ao longo dos anos que sucedeu tal instabilidade política, Fernão Lopes escreveu sobre os antecedentes dessa crise que poderia ter surgido a partir das concepções de monarquia adotadas pelos herdeiros de D. João I e, por mais que sua tarefa fosse "construir a representação dos fatos do passado, ele era homem do seu tempo, desígnio do qual ninguém conseguiu fugir" (GUIMARÃES, 2004, p. 51 $55)$.

\footnotetext{
${ }^{5}$ Há certa discussão referente à data de nascimento do cronista. A data que utilizo neste artigo pode ser encontrada no portal www.fernaolopes.fcsh.unl.pt - página virtual desenvolvida pelo Instituto de Estudos Medievais da Universidade Nova de Lisboa e cuja proposta é disponibilizar informações biográficas sobre o Fernão Lopes e traduções de suas crônicas.
} 


\section{O poder na Idade Média}

\section{Portugal 1300: Poder e Escassez no final da Idade Média}

Por fim, é importante levar em consideração que Fernão Lopes escreve durante o contexto político de legitimação da dinastia de Avis: a dinastia de Borgonha, iniciada com D. Afonso Henriques, teve seu fim após problemas de sucessão por conta da morte do rei D. Fernando em 1383. O impasse resultou numa série de acontecimentos entre 1383 e 1385 que tornariam rei de Portugal o Mestre de Avis, D. João I, filho bastardo de D. Pedro I (SOUZA e NASCIMENTO, 2020, p. 577-581). De acordo com Antônio José Saraiva, Fernão Lopes acabou sendo o encarregado de legitimar uma dinastia que carregava o peso da ilegitimidade, construindo um monumento narrativo que deveria ser referência para as próximas gerações portuguesas (SARAIVA, 1988, p. 166). Tendo em mente tal objetivo Lopes constrói uma representação de D. João I como um Messias de Lisboa, buscando sempre caracterizálo como um rei legítimo.

Rui de Pina, autor da Crônica de D. Afonso V, que utilizamos nesse artigo, também estabeleceu laços com a monarquia portuguesa ao longo de sua vida. Laços, estes, que já haviam começado a ser construídos por seu pai e irmãos antes de seu nascimento. Em 1433, Lopo Fernandes de Pina, pai de Rui de Pina, foi nomeado uchão ${ }^{6}$ da casa do Infante D. Pedro e, após a mencionada batalha de Alfarrobeira, se recolheu à Guarda. Alguns anos depois, em 18 de outubro de 1462, Lopo Fernandes foi nomeado escudeiro do rei D. Afonso V e tornou-se "recebedor das dízimas dos portos da Beira" (ALMEIDA, 1977, p. V-X) e, em 1463, foi designado como coudel de Castel Mando, Castel Bom e Jarmelo. Por fim, em 1483, sob o governo de D. João II, exerceu como juiz dos órfãos da Guarda. Fernão de Pina, irmão mais velho de Rui de Pina, aparece em 1482 como membro da embaixada de D. João II em Montemor para confirmar as alianças antigas com a Inglaterra, e, em 1490, foi mediador de uma

\footnotetext{
${ }^{6}$ O Uchão era o oficial que tinha a seu cargo a ucharia ou despensa do rei, ou seja, era o responsável por ordenar a organização e conservação das carcaças obtidas nas caças, por exemplo.
} 


\section{O poder na Idade Média}

Rudyard Rezende Vera

missão confidencial na África "em que estava jogada a entrega fictícia de Ceuta" aos mouros (ALMEIDA, 1977, p. V-X).

A data de nascimento de Rui de Pina é incerta, mas costumam situá-la em torno de 1440. Já em 1456, com aproximadamente 16 anos, o futuro cronista português já formava relações com a nobreza portuguesa, sendo nomeado escudeiro da Infante Dona Brites. Em 1481, já adulto, Rui de Pina tornou-se escrivão da câmara do príncipe D. João e foi, anos mais tarde, encarregado de analisar as capitulações das pazes acordadas em 4 de setembro de 1497 que punham fim aos conflitos entre D. Afonso V e os Reis Católicos, Fernando II de Aragão e Isabel de Castela, iniciada pela intervenção $D$. Afonso $V$ nas questões de sucessão do trono castelhano. Passagem que o cronista viria a desenvolver em sua narrativa da Crônica de D. Afonso V. Ainda no ano de 1497, em 24 de junho, Rui de Pina foi nomeado simultaneamente GuardaMor da Torre do Tombo e Cronista-mor do reino de Portugal. Assim, é importante considerar que, como Fernão Lopes, Rui de Pina também vivenciou um período histórico agitado e interveio diretamente nos acontecimentos de sua época, podendo "apreciar e julgar os homens, os do seu tempo e os do passado" (ALMEIDA, 1977, p. X$X X I I)$.

Finalmente, foi a partir da narrativa desses homens, que escreveram seus textos rodeados por acontecimentos históricos diferentes e que experienciaram formas de governar também distintas que analisaremos as relações de poder nas fontes portuguesas da Baixa Idade Média em tempos de escassez. Relações de poder que transparecem nas ações dos reis e das autoridades locais.

\section{O levantamento do campo semântico nas crônicas}

Nesta sessão do artigo, apresento algumas das menções a guerras, fenômenos 


\section{O poder na Idade Média}

\section{Portugal 1300: Poder e Escassez no final da Idade Média}

climáticos e fenômenos de abastecimento que já foram incluídas no levantamento do grupo "Portugal 1300", buscando evidenciar o comportamento do rei e dos agentes régios que podem ser percebidos nessas ocasiões. É importante ressaltar também que discorro sobre trechos dos documentos que não mencionam a fome diretamente, mas que, a partir da descrição de acontecimentos em determinadas regiões, nos permitem concluir que tais localidades passavam por períodos de carestia.

O seguinte trecho do volume I das Crônicas de D. Fernando serve como exemplo desses fragmentos nos quais a fome apareceu implicitamente: ao narrar a guerra entre D. Henrique e D. Fernando, que durou de 1369 a 1382, o autor descreveu um cerco realizado pelo primeiro sobre "Ciudad Rodrigo" e, logo em seguida, mencionou a baixa quantidade de mantimentos existentes na cidade castelhana, além de afirmar que $D$. Henrique, ao perceber a situação na qual aquela localidade se encontrava, concluir de que não seria útil tomá-la para si:

“El-rei D. Henrique, vendo que com tudo o que Ihe feito havia não a podia tomar, desde ahi pelas grandes chuvas que estorvavam a vinda dos mantimentos de que o arraial era já minguado, determinou de partir d'ali, havendo dois mezes e meio que jazia sobre ella" (LOPES, 1895, p. 123).

A partir desse trecho, pode-se concluir que a chuva, somada ao cerco realizado por D. Henrique, dificultou o abastecimento daquela localidade, que já sofria pela falta de mantimentos ("de que o arraial era já minguado"). Assim, mesmo sem a presença do termo "fome", a leitura do documento permite o entendimento de que a localidade à qual o texto faz menção enfrentava problemas de abastecimento resultantes das condições de clima e guerra, por causa da chuva e do cerco 


\section{O poder na Idade Média}

Rudyard Rezende Vera

promovido por D. Henrique. Essa passagem também é interessante por retratar a discussão conceitual sobre a fome proposta por Ò Grada, historiador econômico que defende que a fome pode ser causada por guerras e ações humanas: de acordo com o autor, mesmo que sintomas como alta de preços, aspecto que dificulta o acesso dos mais pobres aos gêneros alimentícios ou como o aumento no número de mortes por doenças estejam presentes na maior parte das situações de fome, as origens e duração destes fenômenos podem divergir bastante, tornando as ocasiões de guerra e de "agência humana" fatores que devem ser levados em conta na análise da origem dos episódios de carestia (Ò GRADA, 2015, p.1).

Pensando nos fenômenos de abastecimento e na reação dos reis a eles, temos uma passagem interessante na Crônica de D. Afonso V, escrita por Rui de Pina. D. Duarte I, pai de D. Afonso V, morreu em 13 de setembro 1438, quando seu filho tinha apenas 6 anos. Como era comum na época, a mãe de D. Afonso $V$ e esposa do falecido rei, Leonor de Aragão, assumiria a regência do trono português e governaria até a maioridade de $D$. Afonso $V$, se não fosse pelas disputas regenciais com o Duque de Coimbra, D. Pedro I.

Foi nesse contexto regencial que surgiu a primeira menção a fenômenos de abastecimento dessa crônica: estando as Cortes portuguesas na região de Torres Novas, na província do Ribatejo, no ano de 1438, a então rainha regente Dona Leonor, reconhecendo a carestia de mantimentos em Portugal naquele ano e ciente da alta de preços da região em que estava, transferiu as Cortes para Lisboa. De acordo com Rui de Pina, a rainha teria percebido que, por conta do mar e de seus "boõs Regedores", Lisboa possuía mantimentos mais baratos e, assim, seria mais proveitoso manter as Cortes ali por enquanto: 


\title{
O poder na Idade Média
}

\author{
Portugal 1300: Poder e Escassez no final da Idade Média
}

\begin{abstract}
"Hum mês, e alguns días mais duráram as Cortes em Torres Novas, em fym das quaaes, por sér o ano de mantimentos muy esteril, e aquella Comarca muy cara, acordou a Rainha, e os Ynfantes de se hirem, como foram, com ElRey pera Lixboa, honde per via do mar com yndustria, e avyamento de boõs Regedores, se buscou rezoado provymento, que deu causa serem hi os mantymentos em menos careza, que em alguma outra parte do Regno." (PINA, 1977, p. 605).
\end{abstract}

A partir da leitura desse trecho, se torna possível perceber como, ao mostrar-se ciente das dificuldades pelas quais o reino de Portugal passava, Dona Leonor foi capaz de se adaptar às intempéries e mobilizar as Cortes para uma região mais favorável e com melhores administradores, os ditos "boõs Regedores". Passagem similar está presente na crônica de D. João II, escrita por Garcia de Resende:

“Porque na cidade de Evora começaram a morrer de peste, El-Rei com sua côrte no Janeiro seguinte de quatrocentos e oitenta e dois se foi a Montemóro-Novo para ahi acabar de despachar as cousas particulares das côrtes, e assi ordenar outras que para bem de seus reinos e estados cumpriam" (RESENDE, 1902, p. 73).

O cronista nos descreve como, sendo avisado das mortes por peste em Évora em 1482, D. João II retirou as Cortes portuguesas dessa cidade e transferiu-as para Montemor, onde terminou de "despachar as cousas particulares das côrtes, e assi ordenar outras que para bem de seus reinos e estados cumpriam" (RESENDE, 1902, p. 73) e, assim, evitou a possibilidade de ser contaminado pela peste que se espalhava pela cidade em que antes estava. Contudo, ambos os excertos tratam de ações reais que mobilizaram apenas as Cortes para contornar os problemas pelos quais passava o reino de Portugal em seus respectivos períodos. 


\title{
O poder na Idade Média
}

Rudyard Rezende Vera

Vejamos agora a agência real voltada para a solução dos problemas dos camponeses. Ao tratar dos acontecimentos do reinado de D. Fernando, de 1367 a 1383, Fernão Lopes relata momentos em que, devido à situação de necessidade do reino, o rei foi obrigado a fixar os preços dos alimentos:

\begin{abstract}
"E disse que, porquanto era direito escripto que cada um deve de ser constrangido para vender as cousas que tiver para uso e mantimento dos homens por preço aguisado em tempos de necessidade, que porém mandava que todo o pão dos rendeiros e dos outros, que o tivessem em celeiros e encovado, fosse vendido primeiramente, e depois que este falecesse que então constrangesse mos que tivessem de sua colheita, se mister fizesse" (LOPES, 1895, p. 179).
\end{abstract}

Além disso, o rei também tomou providências visando "impedir a exploração do consumidor pelo intermediário e para colocar cereais em mercado; todo o pão encovado teria de ser posto à venda pelos preços estabelecidos; esgotado este, seriam obrigados os lavradores a vender o cereal de suas novidades" (MARQUES, 1968, p. 259). Antônio H. Oliveira Marques, no capítulo 11 de sua "Introdução à História da Agricultura em Portugal", relata como essa conjuntura para a qual D. Fernando buscava soluções foi causada pelo próprio rei português e suas "aventuras guerreiras". De acordo com o historiador, "não apenas as requisições forçadas de viandas para o exército e para as galés, como também as devastações da guerra, originaram uma falta de todos os mantimentos e subida geral de preços, que a desvalorização ainda acentuava" (MARQUES, 1968, p. 259). Se recorrermos à fonte, Fernão Lopes conta como tal conjuntura foi fruto das medidas econômicas adotadas por D. Fernando que, durante a guerra contra D. Henrique de Castela, "Ihe conviera mandar fazer moedas de desvairadas leis e preços, por melhor poder pagar as 


\title{
O poder na Idade Média
}

\section{Portugal 1300: Poder e Escassez no final da Idade Média}

contias e soldos e as outras despesas que lhe para tal guerra eram pertencentes" (LOPES, 1895, p. 177-178). Em seguida, o cronista relata como D. Fernando, por "desencarregamento de sua consciência e em prol de seu povo", reestruturou o sistema monetário português:

\begin{abstract}
"Então mandou que as moedas que foram feitas em Lisboa e em Valença e no Porto valessem por esta guisa, a saber: os dinheiros que chamavam graves, que valiam quinze soldos dos dinheiros affonsis, que não valessem mais de sete, e as barbudas que valiam vinte soldos tornassem a valer quatorze; e os pilartes, que valiam cinco soldos, valessem três e meio; e os reaes de prata oito soltos" (LOPES, 1895, p. 178).
\end{abstract}

Contudo, mesmo após essa medida, as reclamações populares continuaram e levaram o rei a fixar o preço dos alimentos:

\begin{abstract}
"E vendo el-rei que, não embargando este abaixamento das moedas, pelo costume que as gentes tinham de vender as cousas por preços desaguisados, olhando mais taes pessoas a própria prol que o bem comunal que todos devem desejar a querer, e que tarde ou nunca abaixariam d'elles, orneou almotaçaria em todas as cousas" (LOPES, 1895, p. 178-179).
\end{abstract}

A leitura da crônica de D. Fernando nos leva a crer que o rei, compadecido pelas dificuldades de seu povo e, nas palavras de Fernão Lopes, "olhando elle n'isto serviço de Deus" (LOPES, 1895, p. 178-179), agiu de maneira justa e mobilizou suas forças para melhorar a qualidade de vida de seus súditos. Entretanto, pensando na conjuntura de guerra de Portugal contra Castela, pode ser possível ponderar se essa ação real não foi uma tentativa de conquistar o apoio da população, ou ao menos não 


\section{O poder na Idade Média}

Rudyard Rezende Vera

ganhar sua inimizade, tendo em vista que a guerra entre D. Fernando e D. Henrique durou até 1382 e, o fragmento, trata de medidas reais em 1371. Essa passagem também nos remete ao já mencionado estudo de Ò Grada, tendo em vista que as dificuldades sofridas pela população camponesa tiveram sua origem em um episódio de guerra, que ocasionou uma alta nos preços e dificultou o acesso dos mais pobres aos alimentos.

Temos um trecho similar a esse na Crônica de D. Pedro I, também de Fernão Lopes. Durante a descrição das virtudes do rei, com grande enfoque na justiça empregada pelo monarca, o cronista nos conta que D. Pedro I tinha vontade de manter um povo justo e "extremadamente fazer direito de si mesmo" (LOPES, 1895, p. 29). Logo em seguida, narra-se como o monarca tinha consciência de que os nobres e fidalgos prejudicavam o restante do povo português quando tomavam seus produtos (principalmente gêneros alimentícios) por um preço menor do que aquele que os vendedores cobravam. Assim, D. Pedro I ordenou pena de prisão e multas para os nobres que praticassem tais atos, enquanto os "gallinheiros e pessoas vis" (LOPES, 1895, p. 29-30) que fossem pegos nessa prática seriam açoitados e perderiam seus direitos:

\footnotetext{
"E porquanto elle sentia que o mór agravo que elle e seus filhos, e outros alguns de seu senhorio, faziam aos povos de sua terra, assim no tomar das viandas por preço mais baixo do que se vendiam, que porém elle mandava que nenhum de sua casa, nem dos infantes, nem d'outro nenhum que em sua mercê e reinos vivesse, que cargo tivesse de tomar aves, que não tomasse galinhas, nem patos, nem cabritos, nem leitões, nem outras nenhumas cousas acostumadas de tomar, salvo compradas á vontade de seu dono; e sobre isto pôz pena de prisão, e dinheiros, ás honradas pessoas, e aos gallinheiros e pessoas vis, açoutados pelo logar hu as tomassem, e deitados fora de sua mercê" (LOPES, 1895, p. 29-30).
} 


\section{O poder na Idade Média}

\section{Portugal 1300: Poder e Escassez no final da Idade Média}

É importante ponderar, contudo, sobre a possibilidade de interpretar esse auxílio aos camponeses como forma de reforçar o poder do rei. Buchanan Sharp, analisando as políticas da coroa inglesa voltadas para o mercado de alimentos a partir de 1250, afirma que há poucas evidências de que as regulamentações de mercado realmente visassem o benefício dos pobres. De acordo com ele, essas políticas tinham a intenção de expandir a autoridade real. O discurso de proteção aos pobres, com os quais a Coroa assumia um papel de responsabilidade a partir da regulamentação dos preços, seria um meio de atingir esse objetivo (SHARP, 2012, p. 629-630). Pere Benito i Monclús, por sua vez, complementa essa interpretação de Buchanan Sharp e afirma que as repostas dos reis para a carestia se justificavam publicamente pela "retórica del bien común"7 e pelo dever do governante de promover o bem-estar de seus súditos. Dessa forma, Pere Benito defende a possibilidade de classificar essas medidas como "políticas públicas" (MONCLÚS, 2018, p. 43).

Sobre a reação de seus súditos a essas implementações, Fernão Lopes escreve que estes acreditavam que as penas eram muito rigorosas para crimes tão pequenos e que tais reclamações chegaram até D. Pedro I, que afirmava a importância dessas medidas, tendo em vista que "a pena que os homens mais receavam era a morte, e que se por esta não se cavidassem de mal fazer, que ás outras davam passada, e que boa cousa era enforcar um ou dois, pelos outros todos serem castigados, e que assim o entendia por serviço de Deus e prol de seu povo" (LOPES, 1895, p. 30). Essa afirmação condiz com a imagem de D. Pedro I construída ao longo da crônica escrita Fernão Lopes, em que o monarca português é ilustrado como uma personificação da justiça: “porque a lei é príncipe sem alma, como dissemos, e o príncipe é lei e regra da

\footnotetext{
${ }^{7}$ Sobre a temática da retórica do bem comum, ver: SHARP, B. Famine and Scarcity in Late Medieval and Early Modern England. The Regulation of Grain Marketing, 1256-1631. Cambridge: Cambridge University Press, 2016, pp. 88-89, 103, 130 e 220; e MONCLÚS, Pere Benito i. El Rey frente à la Carestía. Políticas Frumentarias de Estado em la Europa Medieval. Lérida: Milenio, 2018.
} 


\title{
O poder na Idade Média
}

Rudyard Rezende Vera

justiça com alma" (LOPES, 1895, p. 12). É bastante evidente, ao longo da crônica, a maneira pela qual Lopes constrói uma imagem de D. Pedro I de Portugal como um rei justo - apesar de algumas ressalvas, como a cruel execução dos assassinos de Inês de Castro - em oposição ao rei D. Pedro de Castela, que é retratado como um monarca egoísta e tirano (VIEIRA, 2011, p. 87-101). Além disso, se voltarmos algumas páginas, é possível notar como Fernão Lopes identifica nessa característica justa do rei, exemplificada pela ação real de criminalizar os abusos contra os camponeses, um elemento unificador do povo português. Assim, por mais que a língua e a terra fossem elementos facilitadores dessa unidade, seu ponto nevrálgico estava no rei (MATTOSO, 1993, p. 371). Nas palavras no cronista:

\begin{abstract}
"A razão por que esta virtude é necessária nos súbditos, é por cumprirem as leis do príncipe, que sempre devem de ser ordenadas para todo bem, e quem taes leis cumprir sempre bem obrará, cá as leis são regra do que os sujeitos hão de fazer, e são chamadas príncipe não animado, e o rei é príncipe animado, porque ellas representam, com vozes mortas, o que rei diz por sua voz viva: e porém a justiça é muito necessária, assim no povo como no rei, porque sem ella nenhuma cidade nem reino pode estar em socego" (LOPES, 1895, p. 11)
\end{abstract}

Dessa forma, é possível notar no discurso de Fernão Lopes que os súditos também deveriam zelar pelo cumprimento e manutenção das leis, desenvolvidas pelo rei para garantir a justiça e a paz no reino. A partir disso, pode-se ponderar que a monarquia portuguesa da Baixa Idade Média adotava uma postura que gradualmente a tornaria centralizadora politicamente (GUIMARÃES, 2004, p. 16-17).

Outro fragmento que permite relacionar a ação real em tempos de carestia com a centralização política em Portugal pode ser encontrado no volume I da Crônica 


\title{
O poder na Idade Média
}

\section{Portugal 1300: Poder e Escassez no final da Idade Média}

de D. João I, também de Fernão Lopes. Ao narrar uma batalha entre D. João I de Portugal e D. João de Castela, o cronista descreveu como Lisboa sofria com a falta de mantimentos resultante de um cerco organizado pelo rei castelhano em maio de 1384, um ano antes da coroação de D. João I como rei português. Na narrativa fernãolopina os portugueses já estavam sem esperanças de resistência, quando veio o auxílio divino:

\begin{abstract}
"prougue aaquell Senhor que he Primçipe das hostes, e Vemçedor das batalhas que nom ouvesse hi outra lide nem pelleja senom a Sua; e hordenou que o angio da morte estemdesse mais a sua maão e percudisse asperamente a multidom daquell poboo" (LOPES, 1983, p. 310).
\end{abstract}

Com a peste assolando somente o arraial de D. João de Castela e poupando os portugueses cercados, o monarca ordenou a retirada do cerco em setembro do mesmo ano, pois entendeu "que nom prazia a Deos de alli mais estar" (LOPES, 1983, p. 312). No dia seguinte à dissolução do arraial, Fernão Lopes conta como os portugueses organizaram uma procissão para dar graças a Deus e descreve a pregação do Frade Rodrigo de Cintra, da ordem de São Francisco, evidenciando as comparações que o pregador fazia entre o cerco de Lisboa e aqueles sofridos pelas cidades bíblicas de Samaria e Jerusalém:

"E tornamdo ell a comparar per mehudo a carestia e fame de Lixboa, e as outras mimguas e padecimentos com a çidade de Samaria e isso meesmo das outras çidades, e a gram misericórdia que Deos fizera com ella, em nos librar daquela maneira, taaes semelhamças e comparações, nom eram ouvidas, sem gramdes choros e sallucos, e espargimento de muitas lagrimas, de guisa que pareçia gram plamto feito por alguu senhor, alçamdo todos as maãos ao çeeo e damdo muitas graças ao Senhor Deos, que tam gramde misericórdia quisera fazer com elles" (LOPES, 1983, p. 317). 


\section{O poder na Idade Média}

Rudyard Rezende Vera

Assim sendo, na leitura desses acontecimentos narrados na Crônica de D. João transparece "um elemento de propaganda e reforço da piedade geral, e do caráter messiânico da realeza nacional" (BASTOS, 2005, p. 6-7), caracterizando o futuro rei D. João como rei bíblico e Lisboa como uma Jerusalém "cercada e afligida, mas salva afinal pelo apoio ineludível do Senhor ao seu povo eleito" (BASTOS, 2005, p. 6-7). Caracterização que D. João pareceu abraçar, tendo em vista que, já em 1385, ano em que foi coroado, o monarca se afirmava como defensor da ortodoxia religiosa e da saúde daquela cidade que se tornava um destaque do reino em uma carta régia direcionada a Lisboa. Por meio deste documento, o rei português determinou o expurgo dos erros de idolatria que, em sua concepção, originavam a "doença-castigo". Dentre esses erros estava a blasfêmia, pela qual "deos envya ao poboo fomes, e pestelençias e terramotos" (OLIVEIRA, 1887, p. 20).

\section{Conclusão}

Buscamos, ao longo das páginas desse artigo, evidenciar as relações de poder e as ações reais em tempos de escassez e carestia presentes nas fontes portuguesas analisadas no levantamento do projeto "Fome, clima e abastecimento em Portugal no final da Idade Média" (Portugal 1300). Através desse estudo, tentamos mostrar como é possível identificar a resiliência ${ }^{8}$ das comunidades em face das situações de escassez, evidenciando que a população não assistiu passivamente os fenômenos à sua volta, indefesa perante os eventos climáticos, as guerras e aos fenômenos de abastecimento. Além disso, buscamos também evidenciar a capacidade dos monarcas (D. Pedro I, D. Fernando, D. João I e D. Leonor) de, com a ajuda de seus conselheiros, analisar a conjuntura econômica portuguesa do momento em que

\footnotetext{
${ }^{8}$ Uso aqui a definição de resiliência do Dicionário Online de Português: "Capacidade de quem se adapta às intempéries, às alterações ou aos infortúnios". In.: https://www.dicio.com.br/resiliencia/. Acesso em: 18 junho 2020.
} 


\section{O poder na Idade Média}

\section{Portugal 1300: Poder e Escassez no final da Idade Média}

reinavam e, percebendo as origens de alguns dos problemas de abastecimento, que culminavam em situações de carestia, tomar medidas para contornar essas dificuldades. Contudo, é importante lembrar que as crônicas analisadas foram escritas sob encomendas de reis e exaltam o poder da monarquia portuguesa - esse aspecto deve ser levado em conta ao analisarmos as ações reais frente à carestia que, como defendido por Buchanan Sharp e Pere Benito i Monclús, eram usadas muitas vezes como um elemento retórico para fortalecer o rei.

No corpo documental que analisamos, a fome e o abastecimento surgem como ação orquestrada. Isto é, a culpa da carestia não seria da má qualidade da semeadura e da colheita, insuficientes para sustentar a população portuguesa na Baixa Idade Média. O abastecimento não é retratado como um problema agrícola. Os cronistas parecem afirmar que a carestia, nos séculos XIV e XV, pelo contrário, tem sua origem mais associada à ação humana e política, como na utilização da fome como arma de guerra durante os cercos, ou como no aumento dos preços de alimentos durante as Guerras Fernandinas, retratadas na Crônica de D. Fernando, forçando o rei a instaurar a fixação dos preços em tempos de necessidade.

Sendo assim, torna-se possível uma reinterpretação da historiografia de Oliveira Marques, que interpretava a carestia como resultado exclusivo da má qualidade do solo português e da improdutividade da agricultura em Portugal na Baixa Idade Média (MARQUES, 1968, p. 283). As crises agrícolas, nas crônicas reais portuguesas do período, são eventos bem localizados regional e temporalmente, diferentemente da paisagem alimentar portuguesa defendida por uma visão mais generalizadora que atribui ao século XIV um período de carestia geral sentida em todo o reino - mas é importante salientar que, como mencionado, as crônicas reais não tinham o objetivo de descrever exaustivamente os períodos de carestia. 


\section{O poder na Idade Média}

Rudyard Rezende Vera

Buscavam, na verdade, construir uma narrativa que fosse favorável à monarquia portuguesa e, nesse processo, os cronistas acabavam por descrever certas ações reais frente situações de carestias.

Seja através da transferência das Cortes portuguesas, da fixação de preços em tempos de necessidade ou da criminalização do abuso de poder em negociações de produtos, esses monarcas não foram agentes passivos frente a essas conjunturas. Dessa forma, tais passagens servem para reforçar o argumento de David Stone exposto no início desse artigo, já que evidenciam a ação humana frente a situações de carestia, algo desconsiderado pela historiografia da "crise do século XIV" e seus representantes, como Michael Postan e Georges Duby. Ademais, procuramos também demonstrar a possibilidade de identificar um processo de centralização política em Portugal a partir das passagens que representam a ação real em tempos de carestia nas crônicas de Fernão Lopes e Rui de Pina.

\section{Documentos:}

DE PINA, Rui. Crónicas de Rui de Pina. Porto: Lello \& Irmão - editores, 1977.

LOPES, Fernão. Crônica de D. Fernando. 1 v. Porto: Civilização, 1979.

LOPES, Fernão. Crônica de D. Fernando. 2 v. Porto: Civilização, 1979.

LOPES, Fernão. Crônica de D. Fernando. 3 v. Porto: Civilização, 1979.

LOPES, Fernão. Crônica de D. João I. 1 v. Porto: Livraria Civilização Editora, 1983.

LOPES, Fernão. Crônica de D. João I. 2 v. Porto: Livraria Civilização Editora, 1983.

LOPES, Fernão. Crônica de D. Pedro I. Porto: Livraria Civilização Editora, 1895.

OLIVEIRA, Eduardo Freire de. Elementos para a História do Município de Lisboa, Tomo I. Lisboa: Typographia Universal, 1887.

\section{Bibliografia:}




\section{O poder na Idade Média}

Portugal 1300: Poder e Escassez no final da Idade Média

BASTOS, Mario Jorges da Motta. Poder e Doença: Epidemias em tempos de centralização (Portugal - sécs. XIV/XVI). Relações de Poder, Educação e Cultura na Antiguidade e Idade Média. São Paulo: Solis, 2005.

BOIS, Guy. Crise du Féodalisme. Paris: Presses de la Fondation Nationale des Sciences Politiques, 1981.

BOIS, Guy. La Gran Depresión Medieval: siglos XIV-XV. El precedente de uma crisis sistémica. Madrid: Editorial Biblioteca Nueva, 2001.

BOURIN, Monique, DRENDEL, John et MENANT, François (org.) Les Disettes dans la conjuncture de 1300 en Méditerranée Occidentale. Collection de L'École Française de Rome, 450, Roma: École française de Rome, 2011.

BOURIN, Monique, MENANT, François et FIGUEIRAS, Lluís To (org). Dynamiques du Monde Rural dans la Conjoncture de 1300. Échanges, Prélêvements et Consommation en Méditerranée Occidentale. Collection de L'École Française de Rome, 490, Roma: École française de Rome, 2014.

CATARINO, Maria Manuela S. C. Na margem direita do Baixo Tejo: Paisagem Rural e Recursos Alimentares (séculos XIV e XV). Parede: Cascais, 2000.

COELHO, Maria Helena da Cruz. "O Estado e as sociedades urbanas", A Génese do Estado Moderno no Portugal Tardo-Medievo (séculos XIII-XV). Ciclo de conferências, Lisboa: Universidade Autónoma, 1999, p. 269-292.

COSTA, Leonor Freire, LAINS, Pedro e MIRANDA, Susana Münch. História Económica de Portugal. 1143-2010. Lisboa: A Esfera dos Livros, 2011.

GUIMARÃES, Marcella Lopes. Estudo das representações de monarca nas crônicas de Fernão Lopes (séculos XIV e XV). Curitiba: Universidade Federal do Paraná, 2004.

LE GOFF, Jacques (org.). As doenças têm história. Lisboa: Terramar, 1985.

MALEVAL, Maria do Amparo Tavares. Fernão Lopes e a Retórica Medieval. Niterói: Editora de Universidade Federal Fluminense, 2010.

MATTOSO, José. A Nobreza medieval portuguesa - a família e o poder ( $2^{a}$ ed.). Lisboa: Editorial Estampa, 1987. 


\section{O poder na Idade Média}

Rudyard Rezende Vera

MATTOSO, José e SOUSA, Armindo de. História de Portugal. V. Il. Lisboa: Editorial Estampa, 1993.

MARQUES, Antonio $H$. de Oliveira. Portugal na crise dos séculos XIV e XV. Lisboa: Presença, 1986.

MONCLÚS, Pere i Benito. El Rey frente à la Carestía. Polítiacas Frumentarias de Estado en la Europa medieval. Lleida: Milenio, 2018.

MONCLÚS, Pere i Benito. De Labrousse a Sen. Modelos de causalidad e paradigmas interpretativos de las crisis alimentarias preindustriales. Lleida: Milenio, 2018.

Ó GRADA, Cormac. Famine, a short story. Nova Jersey: Princeton University Press, 2009.

Ó GRADA, Cormac. Eating People is Wrong: and other essays of famine, its past, and its future. Oxford e Princeton: Princeton University Press, 2015.

OLIVEIRA MARQUES, Antonio R. Introdução à História da Agricultura em Portugal: a

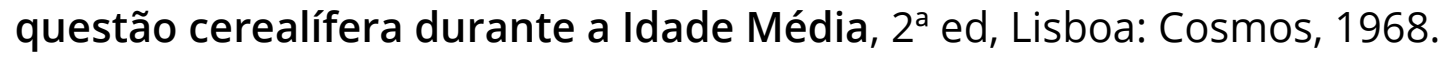

POSTAN, Michel M. Essays on Medieval Agriculture and General Problems of the Medieval Economy. Nova York: Cambridge University Press, 1973.

SARAIVA, Antônio José. O crepúsculo da idade média em Portugal. Lisboa: Gradiva, 1988.

SHARP, Buchanan. Royal paternalism and the moral economy in the reign of Edward II: the response to the Great Famine. Economic History Review, nº 66, vo 2, 2013, pp. 628-647.

SOUZA, Guilherme Queiroz de; NASCIMENTO, Renata Cristina de Sousa (org.). Dicionário: cem fragmentos biográficos. A idade média em trajetórias. Goiânia: Tempestiva, 2020.

STONE, David. Decision-making in Medieval Agriculture. Nova York: Oxford University Press Inc., 2005. 


\section{O poder na Idade Média}

Portugal 1300: Poder e Escassez no final da Idade Média

VERGER, Jacques. Homens e saber na Idade Média. Bauru: EDUSC, 1999.

WOLFF, Phillippe. Outono da Idade Média ou primavera dos tempos modernos? São Paulo: Martins Fontes, 1988. 